\title{
The effects of vegetation density and habitat disturbance on the spatial distribution of ixodid ticks (Acari: Ixodidae)
}

\author{
Kenneth J. Stein ${ }^{1}$, Megan Waterman ${ }^{2}$ Jefferson L. Waldon ${ }^{1}$ \\ ${ }^{1}$ Conservation Management Institute, College of Natural Resources and ${ }^{2}$ Department of Statistics, College \\ of Science, Virginia Polytechnic Institute and State University, Blacksburg, VA 24061, USA
}

\begin{abstract}
Larval, nymphal, and adult Amblyomma americanum (L.), and adult Dermacentor variabilis (Say) ticks were collected using timed dragging techniques, in an attempt to examine how different habitat variables affect models that describe the distribution of ticks in Virginia, USA. Tick count data were modeled using two approaches: (i) habitat and edge, and (ii) habitat, edge, vegetation density and levels of disturbance. Nymphs and adults tended to follow a forest edge distribution when analysed by habitat and edge. Using all variables, we detected a positive relationship with forest edges and negative associations with high-density vegetation. When larvae were modeled by habitat and edge, we failed to detect associations with the edges of habitats. When all variables were included in the larval analysis, disturbed meadow edges emerged as important in the first year, and the categories of disturbed and maturing habitat in the second year. Vegetation density and levels of disturbance were marginally important towards explaining the distribution of nymphs and adults; however, levels of disturbance were potentially more important to the distribution of larvae, than habitat types. Using the habitat and edge variables, and predicted mean encounter rates for all stages of A. americanum and adult D. variabilis, we successfully cross-validated our predictions of high, moderate and low tick densities in both years. The results for nymphs and adults were combined to develop a colour-coded threat assessment map. We estimated that the majority of ticks were located on 20\% of the landscape. The potential uses of geographical information system-based threat maps are discussed.
\end{abstract}

Keywords: ixodid ticks, geographical information system, habitat characterization, spatial distribution, predictive modeling.

\section{Introduction}

Upon completion of feeding, most ixodid ticks detach from their hosts, drop to the ground and eventually molt to the next stage. If these ticks happen to be gravid females, they will ultimately deposit eggs, which hatch into larvae. Whether completing a molt or hatching from an egg, there is much evidence suggesting that ticks seek hosts not far from their original locations on the landscape (Sonenshine et al., 1966, 1995; Wilson et al., 1972;

Corresponding author:

Kenneth J. Stein

Conservation Management Institute

College of Natural Resources

Virginia Polytechnic Institute \& State University

1900 Kraft Dr., Suite 250, MS0534, Blacksburg, VA 24061, USA

Tel. +1 440895 0480; Fax +1 4408950480

E-mail: steinkj@earthlink.net
Daniels and Fish, 1990; Falco and Fish, 1991; Bunnell et al., 2003). In the interim, however, their survival depends on their ability to avoid desiccation, excessive moisture, and predators and parasites. Because ticks spend a small proportion of their lives attached to hosts (Norval, 1974; Sonenshine, 1993), the location of ticks in an ecosystem, indeed, where they survive, is a measure of habitat suitability (Estrada-Peña and Venzal, 2007).

The distribution of ticks on the landscape follows that of many organisms (Giles, 1978); higher densities are typically found along the edges or ecotones (Semtner et al., 1971b; Sonenshine, 1993). These ecotones are the confluence of two habitats, and are composed of both pioneer and older plant communities. Pioneer plant communities grow rapidly, often forming dense thickets that provide food and shelter for tick hosts, including, mammals, birds and 
reptiles. Some sections of these thickets act as permeable boundaries, impeding or allowing host movement to other habitats. Accordingly, if animal hosts spend more time in ecotones than other areas on the landscape (Leopold, 1933), and if there are permeable sections of these linear features of the landscape, then the numbers of detached and/or questing ticks should be concentrated in these zones.

In recent years, a number of researchers have modeled the intricate relationships among ixodid ticks, their hosts, and various aspects of their environment. These studies have been conducted along a continuum ranging from small scale, microhabitat-based models (Semtner et al., 1971a; Petney and Bull, 1984; Klomp and Bull, 1987; Chilton and Bull, 1993; Daniel and Dusbábek, 1994; Slowik and Lane, 2001) to large scale, landscape-based models (Semtner et al., 1971b; Semtner and Hair, 1973; Koch, 1984; Haile and Mount, 1987; Ostfeld et al., 1995, 1996a,b). For the latter, many of these include data that have been derived from remotely-sensed imagery (Glass et al., 1995; Nicholson and Mather, 1996; Bunnell et al., 2003). Developing small or large-scale vector population models is both difficult and labor-intensive. These difficulties span several disciplines and include field collections, habitat quantification (Daniel and Dusbábek, 1994), and validating models that have been developed from remotely-sensed images. Additional problems stem from the limitations of equipment, and data interpretation issues related to scale, habitat heterogeneity, and oftentimes, a paucity of data (Nicholson and Mather, 1996; Van Buskirk and Ostfeld, 1998; Kitron, 2000). Clearly, there is a critical need for developing modeling techniques that measure how tick populations respond to site specific factors, especially techniques that can be used for both small and large-scale predictions.

Herein we report on methods that classify a large, ecologically diverse area into a reduced number of quantifiable habitats, including their structure and ecological characteristics. This framework was then used to model and eventually predict the combined distributions and densities of the American dog tick
Dermacentor variabilis (Say), and the lone star tick Amblyomma americanum (L.). D. variabilis is a widely distributed vector of Rocky Mountain spotted fever (Sonenshine, 1993), human monocytic ehrlichiosis (Schulze et al., 2006) and has been implicated as the primary vector of tularemia (Hopla and Hopla, 1994). A. americanum is the primary vector of human monocytic ehrlichiosis (Lockhart et al., 1997), and is also a vector of tularemia (Hopla and Hopla, 1994). A. americanum has also been implicated in the transmission of southern tick-associated rash illness (STARI), that results in a clinical condition similar to Lyme disease, and is caused by Borrelia lonestari (Burkot et al., 2001; Childs and Paddock, 2003).

In Virginia, A. americanum nymphs and adults, and $D$. variabilis adults attain their maximum numbers in mid-summer. This season coincides with outdoor military training exercises, civilian recreational activities, and when personnel are most likely to encounter ticks. Although there exists a variety of measures for personnel to reduce exposure to ticks, compliance with these is poor (Gambel et al., 1998). We developed this research, in part, to develop methods for Fort Pickett Maneuver Training Center (Blackstone, Virginia, USA) personnel to identify areas with high threats from tick-borne diseases.

\section{Materials and methods}

\section{Site selection and characterization}

We conducted our study at Fort Pickett Maneuver Training Center, an 18,200 ha military training center near the town of Blackstone, Virginia. Fort Pickett lies on the Piedmont Plateau physiographic province and holds a variety of habitats. We condensed these into five categories: including, (i) forest, (ii) young woodland, (iii) meadow, (iv) wetland, and (v) thicket. The species of vegetation and the characteristics for each habitat category are detailed in Table 1. Forests consisted mostly of hickory (Carya spp.), oak (Quercus spp.) and maple (Acer spp.), and were characterised by the presence of a 
Table 1. Vegetation classification at Fort Pickett, VA ${ }^{\mathrm{a}}$, USA.

\begin{tabular}{|c|c|}
\hline Habitat & Species \\
\hline \multirow[t]{2}{*}{ Forest } & $\begin{array}{l}\text { Canopy: } \\
\text { hickory (Carya spp.), northern red oaks (Quercus rubra L.), sugar maple (Acer saccharum Marsh.), sweet } \\
\text { gum (Liquidambar styraciflua L.), tuliptree (Liriodendron tulipifera L.), white oak (Q. alba L.); including } \\
\text { loblolly pine (Pinus taeda L.) and Virginia pine (Pinus virginiana Mill.) when mixed forest. }\end{array}$ \\
\hline & $\begin{array}{l}\text { Understory: } \\
\text { blueberry (Vaccinium corymbosum L. and V. angustifolium Ait.), cherries (Prunus spp.), dogwood (Cornus } \\
\text { florida L.), holly (Ilex spp.), mountain laurel (Kalmia latifolia L.). }\end{array}$ \\
\hline Young woodlands & Sweetgum, tuliptree, red maple (Acer rubrum L.), loblolly pines, sassafras (Sassafras albidum Nutt.), oaks. \\
\hline Meadows & $\begin{array}{l}\text { Big bluestem (Andropogon gerardii Vitman), little bluestem (Schizachyrium scoparium Michx. (Nash)), } \\
\text { bushy bluestem (A. glomeratus Walt.), Virginia broomsedge (A. virginicus L.), switchgrass (Panicum virga- } \\
\text { tum L.), white clover (Trifolium repens L.), goldenrod (Solidago spp.), Lespedeza (Lespedeza bicolor Turcz. } \\
\text { and L. cuneata (Dumont)), spotted knapweed (Centaurea maculosa Lam.). }\end{array}$ \\
\hline Wetlands & $\begin{array}{l}\text { Grasses and sedges, buttonbush (Cephalanthus occidentalis L.), meadow beauty (Rhexia virginica L.), } \\
\text { smooth alder (Alnus serrulata (Ait.) Willd.), sycamores (Platanus occidentalis L.), various wetland asters } \\
\text { (Eupatorium spp.), willows (Salix spp.). }\end{array}$ \\
\hline Thickets & $\begin{array}{l}\text { Brambles (Rubus spp.), catbrier (Smilax spp.), elderberry (Sambucus canadensis L.), poison ivy } \\
\text { (Toxicodendron radicans (L.) Kuntze), Russian olive (Eleagnus angustifolia (L.)), winged sumac (Rhus } \\
\text { copallina L.), blueberry, saplings, including: red maple, sweet gum, tuliptree, oak. }\end{array}$ \\
\hline Ecotone/edge & $\begin{array}{l}\text { Early-succession complexes of the above species that characterise thickets: brambles, catbrier, poison ivy and } \\
\text { winged sumac. }\end{array}$ \\
\hline
\end{tabular}

aClimax community at Fort Pickett consists of oak, hickory, and pine forests (Braun, 1950).

canopy and an understory. Young woodlands did not contain an understory but possessed the above species, including loblolly pine (Pinus taeda L.) and sweetgum (Liquidambar styraciflua L.). Meadows contained many species of vegetation and chief among these were bluestem grasses (Andropogon gerardii Vitman, A. glomeratus Walt., and Schizachyrium scoparium Michx. (Nash)), switchgrass (Panicum virgatum L.), clover (Trifolium spp.), goldenrod (Solidago spp.), Lespedeza (Lespedeza spp.) and knapweed (Centaurea maculosa Lam.). Wetlands possessed many grasses and sedges, asters (Eupatorium spp.), buttonbush (Cephalanthus occidentalis L.), smooth alder (Alnus serrulata (Ait.) Willd.), sycamores (Platanus occidentalis L.) and willows (Salix spp.). Thickets were a transitional stage for late successional meadows, with extensive numbers of brambles (Rubus spp.), catbrier (Smilax spp.), poison ivy (Toxicodendron radicans (L.) Kuntze), Russian olive (Eleagnus angustifolia (L.)), winged sumac (Rhus copallina L.) and various saplings, especially maples and sweetgum. Ecotones or edges consisted of many early-suc- cessional complexes of the above species and many thicket species; including, brambles, catbrier, poison ivy and winged sumac.

For our study, we selected three primary habitats, three complementary ecotones and one wetland edge habitat (Table 2). We classified edges for each habitat based on noticeable changes in the composition of plant communities. Although each member of the edge pair can be variable in length, width and height, we reported the average ecotonal width used throughout our investigation (Table 2). As ticks are rarely found on aquatic and emergent wetland vegetation, we restricted our sampling to the shoreline. Likewise, we did not sample from the interior of thickets as we considered these impenetrable. During the first year of our investigation, we began to suspect that tick presence varied with (i) vegetation density, and (ii) levels of disturbance among habitats. Accordingly, we gradually introduced these two categories of data collection into our sampling sites during the first year. Since the first year of collecting involved a fixed number of sites, this procedure involved reclassifying all sites in midsummer using the characteristics in Table 2. 
Vegetation density categories (Table 2) are modified from Semtner et al. (1971b).

\section{Tick collections and sampling methodology}

In both years, we visited Fort Pickett every three weeks, beginning in mid-May and through midSeptember. During the first year of our study, we collected ticks from 21 fixed sites, three of which were eventually destroyed by bulldozers and other heavy vehicles. We visited each site ten times $(\mathrm{n}=180)$ and randomised collections among sites such that we did not follow the same site order with each visit. We collected ticks for three consecutive days using $1 \mathrm{~m}^{2}$ white muslin tick drags and timed our walks for $10 \mathrm{~min}$ with a stopwatch. Within this period, an individual walking at a normal pace can easily cover the distance of $\sim 0.75-1.0 \mathrm{~km}$. We checked tick drags every $12-15$ steps, and more fre- quently when vegetation was dense. Upon capture, we placed ticks in coded vials for eventual identification in the laboratory. We removed ticks from clothing at the end of each timed collection and counted these in our study. When collectors were overwhelmed with large numbers of tick larvae, and occasionally, large numbers of nymphs, the specimens were rapidly removed from the tick drag with lint rollers (Evercare Inc., Waynesboro, GA, USA) and placed inside sealable plastic sandwich bags. We characterised habitats, identified plant species and the level of succession at each site, whether these locations were positive for ticks or not. We did not attempt to collect ticks when vegetation was wet from rain or heavy dew.

With respect to tick collection in the first year, we had three objectives:

(i) to develop baseline data;

(ii) to generate presence/absence models; and

Table 2. Habitat classification at Fort Pickett, VA, USA, including structure, characteristics, vegetation density and disturbance ${ }^{\mathrm{a}}$.

\begin{tabular}{|c|c|}
\hline Habitat/ecological zone & Structure and characteristics \\
\hline Forest & $\begin{array}{l}\text { Unfragmented, minimal disturbance, developed canopy and understory, pioneer communities absent, } \\
>8 \mathrm{~m} \text { from edges of other habitats or road. }\end{array}$ \\
\hline Forest edge & $\begin{array}{l}\text { Fragmented, disturbed, barrier-like, pioneer communities present, contiguous with adjacent habitat } \\
\text { edges, }<8 \mathrm{~m} \text { into forest. }\end{array}$ \\
\hline Young woodlands & $\begin{array}{l}\text { Unfragmented, saplings to medium size trees, no canopy or understory, grasses and forbs present, }>4 \mathrm{~m} \\
\text { from edges of other habitats or road. }\end{array}$ \\
\hline Young woodland edge & $\begin{array}{l}\text { Fragmented, saplings to medium size trees, no canopy or understory, grasses and forbs present, con- } \\
\text { tiguous with adjacent habitat edges, }<4 \mathrm{~m} \text { into young woodland. }\end{array}$ \\
\hline Meadows & Unfragmented, grasses and forbs, saplings and thickets absent, $>2.5 \mathrm{~m}$ from edges of other habitats or road. \\
\hline Meadow edge & $\begin{array}{l}\text { Fragmented, grasses and forbs, saplings and thickets present, contiguous with adjacent habitat edges, } \\
<2.5 \mathrm{~m} \text { into meadow. }\end{array}$ \\
\hline Wetland edge & Variable structure, wetland vegetation, $<4.5 \mathrm{~m}$ from water, edges of other habitats and roads. \\
\hline \multicolumn{2}{|l|}{ Vegetation density } \\
\hline Low density & $\begin{array}{l}0-<25 \% \text { coverage: bare ground is apparent in all habitats, or covered with pine needles and leaf litter, } \\
\text { few grasses, forbs and saplings. }\end{array}$ \\
\hline Moderate density & $25-75 \%$ coverage: bare ground is absent in all habitats, can walk through all habitats easily. \\
\hline High density & $\begin{array}{l}>75 \% \text { coverage: grasses, forbs, saplings and shrubs in all habitats; all habitats require much effort to } \\
\text { walk through. }\end{array}$ \\
\hline \multicolumn{2}{|r|}{ (10 } \\
\hline Disturbed & Evidence of human-related disturbances, heavy deer use/browsing and storm damage. \\
\hline Undisturbed & Few recent disturbances, appearance is characteristic for habitat, transitional vegetation is rare or absent. \\
\hline Maturing & Transitional stage, most vegetation is early successional, almost ecotonal. \\
\hline Near-pristine & Similar to undisturbed, with no observable disturbances. \\
\hline
\end{tabular}

${ }^{a}$ Climax community at Fort Pickett consists of oak, hickory and pine forests (Braun, 1950). 
(iii) to develop tentative predictions for population densities.

The latter was of particular importance as we sought to model tick distribution as a function of habitat, vegetation density, and levels of disturbance as in Table 2. The primary objective for the second year collections was to cross-validate the count data predictions that we developed during the first year. Accordingly, the second year collections were unique insofar as we sampled each of 136 sites once, and spent $350 \mathrm{~min}$ in each of the seven habitat/edge categories listed in Table 2.

\section{Modeling techniques}

We modeled all tick count data using generalized estimating equations (GEE) with the GENMOD procedure of SAS (SAS, 1998). Four indicator variables, including forest, young woodland, meadow and the primary (non-edge) aspects of the habitat, were used to model adults, nymphs and larvae by habitat/ecological zone. When these models, included vegetation density and levels of disturbance, the additional indicator variables consisted of high and low density and disturbed, undisturbed and maturing, respectively. We chose baseline values as follows: wetlands for habitat, edge for ecological zone, moderate for vegetation density, and near-pristine for level of disturbance. Because of the near similarity between the undisturbed and near-pristine levels of disturbance, we conducted an additional test after combining these categories as a separate baseline value. When the model coefficients were both significant and negative, this impacted the model by lowering the corresponding prediction.

Parameters having P-values greater than 0.10 were removed from the final model using a backwards variable selection method.

Adults and nymphs followed a Poisson distribution with a log link function. We modeled A. americanum larvae differently due to the large variability in larvae counts. When A. americanum larvae attach to a tick drag, they typically attach in clumps that number in the hundreds, minimally in the tens.
Accordingly, we categorized larvae in two groups; they were assigned a value of 1 if the count was $\geq 1$, otherwise they were assigned a 0 . Larvae were modeled using a binomial distribution with a logit link. Wald chi-square tests were used to determine whether a parameter differed significantly from zero.

We used the FREQ procedure (SAS, 1998) to cross-validate the count data predictions for both years (Kleinbaum et al., 1998), basing our predictions on the numbers of ticks expected within a 10 min collection period. For nymphs and adults we set cut-off points as follows: $0-1$ ticks = low; $2-4$ ticks = moderate; and $>4$ ticks $=$ high. For larvae we used the following criteria: $0-1$ ticks = low; $2-10$ ticks = moderate; and $>10$ ticks $=$ high. Predictions for the adults and nymphs were calculated by raising $e$ to the sum of the products of corresponding coefficients and indicator variables. Predictions for the larvae were calculated by setting the logit equal to the sum of the products of corresponding coefficients and indicator variables.

We report on two sets of results for count data predictions, and refer to these as predicting and conditional predicting. The former resulted from the correct matching of observed counts with the expected categories of low, moderate, and high. The latter included the correctly matched counts as above, and the values that resulted from predicting high, and observing low and moderate and predicting moderate, and then observing low. Conditional predicted values provide conservative estimates resulting in a "maximum" level of threat, albeit this threat level may be significantly higher than the actual surroundings. We used the chi-square test of independence and the likelihood ratio chi-square test (Agresti, 2002) to determine whether a relationship existed between the observed and expected categories (high, moderate and low).

\section{Geographical information systems (GIS)}

Throughout this investigation, we wanted to develop criteria that made sense for personnel in the field, and accordingly, we did not test other cut-off points. 
Our moderate thresholds for adults agree with mean encounter rates for $A$. americanum of 1.8 adults per $10 \mathrm{~min}$ (11 per hour) reported by Stromdahl et al. (2000). We used a digital orthophoto and a digital vegetation layer (Morton, 1998) for delineating all habitats. We also recorded habitat data on site with a global positioning system (GPS), to modify habitat categories that were either not included, or may have differed from the above database. We combined all significant habitat variables and count data predictions, and represented these as colour-coded threat polygons. All polygons were created within the GIS by a technique of buffering the boundaries between habitats based on distance (Table 2) using ArcGIS 9.1 (ESRI Inc., Redlands, CA, USA), with an onscreen display scale of 1:2000. The Arcview query function was used to estimate the area of each threat polygon as a percentage of the total map area.

\section{Results}

We collected two tick species during our study, A. americanum and D. variabilis; larvae, nymphs and adults of the former, and adults of the latter. We analysed both adult species separately before combining our results in Tables 3 and 4. In 1998, the GEE model predicted high, moderate and low categories for $D$. variabilis. The same model only predicted the low category for A. americanum at all 18 sites, despite some counts in the moderate and high categories. When we combined both species the model correctly predicted high, moderate and low categories, in both years. The results in Table 3 describe tick models as a function of habitat and edge. The results presented in Table 4 contain these same variables and include the effects of vegetation density and disturbance.

In both years, forest edges were important to the distribution of adults and nymphs (Table 3), and several relationships emerged when vegetation density and disturbance were included in the model. Forests became the predominant habitat for adults and nymphs, and we detected significant negative relationships with high-density vegetation in three of four analyses (Table 4), excepting adults in 1998. Edge remained a significant independent variable in all analyses, except for nymphs in 1999, when it was replaced by significant negative relationships with high-density vegetation, and both disturbed and undisturbed habitats (Table 4). Reciprocally, nymph distributions followed low-to-moderate density vegetation in maturing forests. The analyses for adults in 1999 revealed significant associations with all levels of disturbance, which suggest an equal distribution among these categories (Table 4). A summary of the results presented in Tables 3 and 4, suggests that nymphs and adults tend to "prefer" forest edges, and both "avoid" high-density vegetation.

Distributions of $A$. americanum larvae differed from those of the adults and nymphs. In both years, A. americanum larvae were significantly associated with the primary aspects of forests and meadows, including young woodlands in 1999 (Table 3). These results changed when all variables were included in the model (Table 4). We report significance for both years, the categories of meadow edge and disturbed in 1998, and disturbed and maturing in 1999.

For the ticks collected in 1998, our observations matched the predictions for the categories of low, moderate and high, using the FREQ procedure as follows: for adults $(69 \%)$, nymphs $(67 \%)$ and larvae $(43 \%)$. We obtained slightly different results using conditional predicting. All values increased, for adults $(78 \%)$, nymphs $(90 \%)$, and larvae $(98 \%)$. For the ticks collected in 1999 , our observations matched the categories of low, moderate and high; for adults (58\%), nymphs (68\%) and larvae $(48 \%)$. When we included conditional predictions as above, all values increased for adults $(78 \%)$, nymphs $(95 \%)$ and larvae $(98 \%)$. When we compared the observed and expected categories of high, moderate and low, the chi-square test of independence yielded significant results for all stages: adults (chi-square $=26.89 ; \mathrm{df}=4 ; \mathrm{P}<0.001$ ), nymphs (chisquare $=42.40 ; \mathrm{df}=4 ; \mathrm{P}<0.001$, and larvae (chisquare $=6.78 ; \mathrm{df}=4 ; \mathrm{P}=0.037)$. Additional analyses using the likelihood ratio chi-square test produced similar, low P-values. 
Combining the undisturbed and near-pristine levels of disturbance and then testing these as a single baseline value produced the following results. For the ticks collected in 1998, our observations matched the predictions for the categories of low, moderate and high as follows: for adults $(80 \%)$, nymphs $(74 \%)$ and larvae $(59 \%)$. We obtained mixed results using conditional predictions. The val-

Table 3. Significant values for all stages of $A$. americanum and adult D. variabilis ticks when modeled by habitat and ecological zone.

\begin{tabular}{|c|c|c|c|c|c|c|c|c|c|}
\hline Year & Stage & $\begin{array}{l}\text { Forest } \\
\left(\text { SEM }^{*}\right)\end{array}$ & P-value & $\begin{array}{l}\text { Young woodland } \\
\text { (SEM*) }\end{array}$ & P-value & $\begin{array}{l}\text { Meadow } \\
\left(\text { SEM }^{*}\right)\end{array}$ & P-value & $\begin{array}{c}\text { Primary }{ }^{\mathrm{b}} \text { (non-edge) } \\
\left(\mathrm{SEM}^{*}\right)\end{array}$ & P-value \\
\hline \multirow[t]{3}{*}{1998} & Adults & $\begin{array}{c}0.858 \\
(0.158)\end{array}$ & $<0.001$ & & & & & $\begin{array}{l}-0.741 \\
(0.297)\end{array}$ & 0.013 \\
\hline & Nymphs & $\begin{array}{c}3.120 \\
(0.757)\end{array}$ & $<0.001$ & $\begin{array}{l}-1.071 \\
(0.403)\end{array}$ & 0.008 & $\begin{array}{c}-0.666 \\
(0.240)\end{array}$ & 0.006 & $\begin{array}{l}-1.785 \\
(0.898)\end{array}$ & 0.047 \\
\hline & Larvae & $\begin{array}{l}1.386 \\
(0.437)\end{array}$ & 0.002 & & & $\begin{array}{c}2.197 \\
(0.786)\end{array}$ & 0.005 & & \\
\hline \multirow[t]{3}{*}{1999} & Adults & $\begin{array}{c}1.556 \\
(0.169)\end{array}$ & $<0.001$ & $\begin{array}{c}0.953 \\
(0.245)\end{array}$ & $<0.001$ & $\begin{array}{c}0.976 \\
(0.215)\end{array}$ & $<0.001$ & $\begin{array}{c}-1.336 \\
(0.284)\end{array}$ & $<0.001$ \\
\hline & Nymphs & $\begin{array}{c}1.691 \\
(0.195)\end{array}$ & $<0.001$ & & & & & $\begin{array}{l}-0.728 \\
(0.308)\end{array}$ & 0.018 \\
\hline & Larvae & $\begin{array}{c}2.849 \\
(0.481)\end{array}$ & $<0.001$ & $\begin{array}{c}1.981 \\
(0.427)\end{array}$ & $<0.001$ & $\begin{array}{c}3.738 \\
(0.810)\end{array}$ & $<0.001$ & & \\
\hline
\end{tabular}

aAn empty cell indicated that the parameter associated with this variable had a P-value larger than 0.10 , and was removed from the final model;

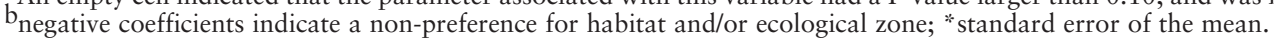

Table 4. Significant values for all stages of A. americanum and adult D. variabilis ticks when modeled by habitat, ecological zone, vegetation density and level of disturbance.

\begin{tabular}{|c|c|c|c|c|c|}
\hline Year & Stage & Variables $^{\mathrm{a}}$ & Coefficients ${ }^{\mathrm{b}}$ & SEM* & P-value \\
\hline \multirow[t]{8}{*}{1998} & \multirow[t]{2}{*}{ Adults } & Forest & 1.246 & 0.327 & $<0.001$ \\
\hline & & Primary (non-edge) & -1.061 & 0.424 & 0.012 \\
\hline & \multirow[t]{3}{*}{ Nymphs } & Forest & 5.740 & 3.086 & 0.065 \\
\hline & & Primary (non-edge) & -1.256 & 0.687 & 0.067 \\
\hline & & High density & -1.986 & 0.939 & 0.035 \\
\hline & \multirow[t]{3}{*}{ Larvae } & Meadows & 1.974 & 0.826 & 0.017 \\
\hline & & Primary (non-edge) & -1.692 & 0.759 & 0.026 \\
\hline & & Disturbed & 2.187 & 0.578 & $<0.001$ \\
\hline \multirow[t]{12}{*}{1999} & \multirow[t]{6}{*}{ Adults } & Forest & 0.603 & 0.219 & 0.006 \\
\hline & & Primary (non-edge) & -1.327 & 0.271 & $<0.001$ \\
\hline & & High density & -0.661 & 0.275 & 0.016 \\
\hline & & Disturbed & 1.040 & 0.182 & $<0.001$ \\
\hline & & Maturing & 1.081 & 0.214 & $<0.001$ \\
\hline & & Undisturbed & 1.175 & 0.031 & $<0.001$ \\
\hline & \multirow[t]{4}{*}{ Nymphs } & Forest & 3.681 & 0.272 & $<0.001$ \\
\hline & & High density & -2.164 & 0.536 & $<0.001$ \\
\hline & & Disturbed & -2.325 & 0.320 & $<0.001$ \\
\hline & & Undisturbed & -2.326 & 0.536 & $<0.001$ \\
\hline & \multirow[t]{2}{*}{ Larvae } & Disturbed & 3.541 & 0.502 & $<0.001$ \\
\hline & & Maturing & 2.32 & 0.367 & $<0.001$ \\
\hline
\end{tabular}

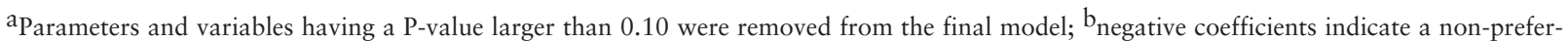
ence for habitat, ecological zone, density, or disturbance; "standard error of the mean. 
ues for adults were the same $(80 \%)$, and the values for nymphs $(89 \%)$ and larvae $(100 \%)$ were higher. For the ticks collected in 1999, our observations matched the categories of low, moderate and high; for adults $(62 \%)$, nymphs $(76 \%)$ and larvae $(39 \%)$. When we included conditional predictions as above, the values for adults were the same $(62 \%)$, and those for nymphs $(88 \%)$ and larvae $(97 \%)$ were higher. The similarity between the test data (1999) and training data (1998) percentages, validates the models that were developed from both the near-pristine and undisturbed/near-pristine baselines.

The above analyses for nymphs and adults were depicted as threat polygons in a 24 ha region of Fort Pickett, known as the Twin Lakes area (Fig. 1). We did not attempt to map larvae since the results were not consistent between analyses. Queries for each edge polygon produced the following results that were expressed as percentages: high threat forest edge (red) $14.4 \%$; moderate threat meadow edge (orange) $3.6 \%$; and low threat wetland edge (yellow) $1.5 \%$. When combined, these polygons represent $20 \%$ of the mapped area.

\section{Discussion}

The spatial distributions that we report for $A$. americanum and $D$. variabilis nymphs and adults are consistent with the body of literature (Semtner et al., 1971b; Sonenshine and Levy, 1972; Campbell and Mackay, 1979). In addition, Semtner et al. (1971b) suggested that tick distributions were largely influenced by movements of white-tailed deer Odocoileus virginianus Zimmerman, the primary host for all stages of $A$. americanum among different geographical locations (Patrick and Hair, 1979; Bloemer et al., 1988). It has been reported that deer spend much of their time associated with ecotones (Bartlett, 1938), although radio-telemetry studies involving deer have subsequently revealed daily and seasonal variation among regional populations.

There exists a working hypothesis that movements of vertebrate hosts, determine the distribution of ticks (Estrada-Peña, 2002; Bunnell et al., 2003).
Semtner and Hair (1973) reported that the locations where engorged $A$. americanum females and nymphs have detached from deer in the spring and early summer will determine the distribution of larvae later that summer and adults the following spring. It is not as easy to comprehend the distribution of $D$. variabilis as a function of host movements, since it has several principal hosts, including mice, voles, chipmunks and rabbits. The edge-related ecology of these mammals has been well-studied, and one can envision much interaction with the edges of meadows, forests and wetlands. In the absence of distribution studies, however, it seems reasonable to suggest that the locations where ticks detach from their hosts or deposit their eggs is random within host-occupied areas, thus, proportional to the area of each habitat type.

Our attempts to identify additional relationships by including vegetation density and disturbance in our model produced mixed results and consistent patterns were not apparent. The significant negative relationship with high-density vegetation for nymphs and adults in three of four analyses indicates that, perhaps, tick hosts did not frequently use these areas, or these areas were not conducive to survival. For nymphs in 1999 (Table 3), our findings suggest that densities in maturing habitats were similar to densities in ecotonal or edge-like habitats, or those habitats in a transitional stage (Table 2). So, for this analysis, the maturing category may be equivalent with edge. Although the inclusion of the above variables revealed additional relationships or probable trends, these may be of minimal importance to the population. The most apparent changes observed in this study concerned distributions of A. americanum larvae. The replacement of primary habitats with the categories of edge and disturbed in 1998, and disturbed and maturing in 1999, suggests that disturbed and maturing habitats are potentially more important to the distribution of larvae than the primary aspects of habitats. Thus, habitats having these qualities must be related to either larval survival or attraction to the host of adult treks (e.g. deer) on which the adults feed, and then lay eggs from which larvae hatch. 


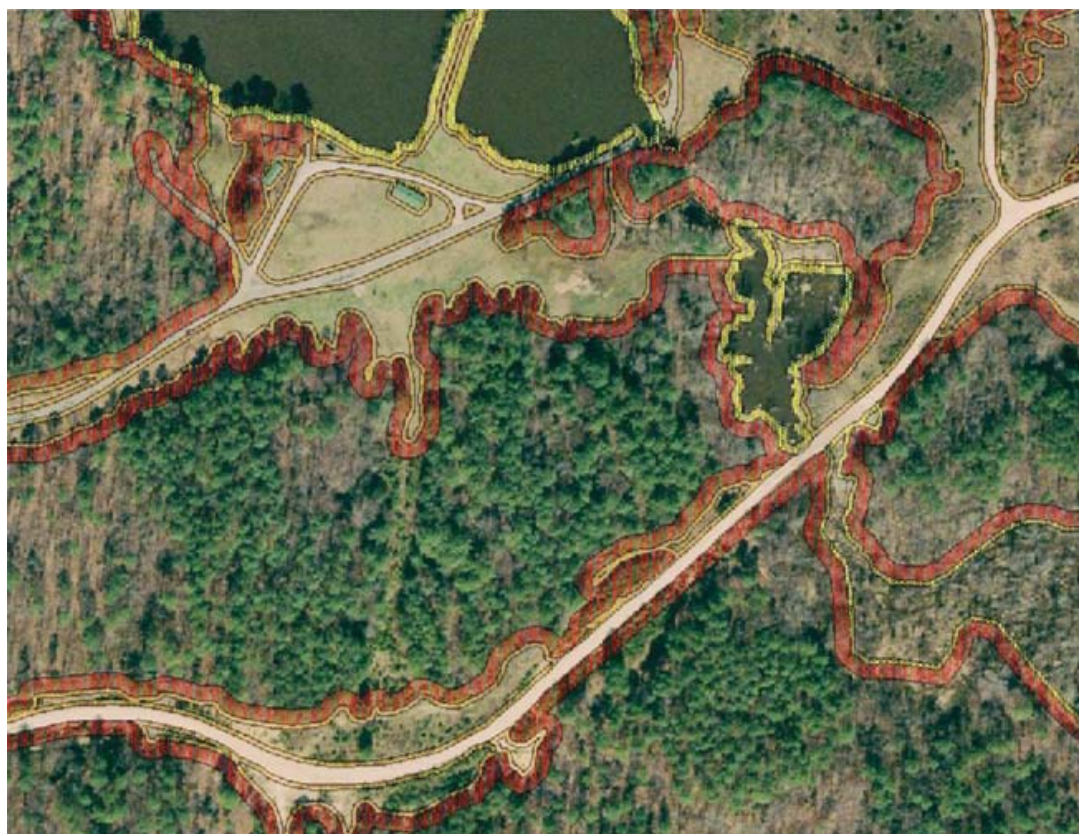

Fig. 1. The spatial distribution of nymph and adult A. americanum and adult D. variabilis based on models and cross-validated count models over a 2-year period. Colours indicate the following tick densities: red - forest edge, high density; orange - meadow edge, moderate density; yellow - wetland edge, low density. Total area for predictions is 24 ha with an onscreen resolution of 1:2000.

In attempting to predict the presence of ticks on the landscape, we hypothesized that where we failed to collect ticks, hosts had never used these areas or tick mortality was very high. Koch (1984) reported that $A$. americanum eggs did not survive in meadows and that larval mortality was greatest in these areas. In Virginia, Sonenshine et al. (1966) compared the distribution of $A$. americanum among four vegetation classifications, and reported that tick densities were lowest in meadow habitats. Similarly, Semtner et al. (1971a) reported that tick survival was lowest in meadow habitats, and attributed the causes to high night-time humidity and low daytime humidity. These reports are convincing, and could suggest that the egg and larval stages of ticks are more affected by microclimatic factors than are nymphs and adults. Once these regulating factors have exerted their influence on the population, then suitable microhabitats would determine survival for the population. Perhaps in time, the population of nymphs and adults would give the appearance of migrating toward edges, when in fact there is a change in proportionate abundance with greatest losses occurring in the least favorable habitats. Surviving ticks would be located in edges or in disturbed or transitional-type patches that possess optimal microclimatic conditions.

In addition to the above, our significant cross-validation of models that predict high, moderate and low counts of ticks by habitat characteristics and time extend those of the literature. Bunnell et al. (2003) predicted presence of Ixodes scapularis Say within $86 \%$ of their study locations in five states, and Estrada-Peña (2002) predicted varying patch densities for I. ricinus in Spain. Our study demonstrated that a significant part of the tick population occupies $\sim 20 \%$ of the map area, with the highest predicted counts for nymphs and adults associated with forest edges, an area comprising $14.4 \%$ of the total map area. These percentages agree with those reported by Goddard (1997). Although some part of the population exists away from the edges, we believe that the 
high threat zones possess important qualities for maintaining the population.

Although our predicted counts were not exact, the results were significantly similar between years, and between types and edges. We also observed similar, even slightly better results after combining the two levels of disturbance into a single baseline value. These results suggest that minor visible differences among levels of disturbance can effect the predictions of a model. Accordingly, we believe that our methods present a useful approach for developing similar models that involve ticks or other disease vectors on the landscape. Threat maps (Fig. 1) have several potential uses, chief of which includes identifying high threat zones for the judicious application of acaricides. The benefits of precisely targeting insecticides are well-known, especially, reducing costs and toxic substances in the environment. Threat maps could also serve as a guide for landscape management. In this case, certain areas on the landscape could be modified such that they would not be conducive to tick survival (Haile and Mount, 1987; Mount et al., 1999). Finally, we believe that these maps could serve as a guide for people to avoid tickinfested areas. In various parks across the United States, and on numerous military installations, personnel have access to brochures or training aids that assist with identifying poisonous plants, snakes and insects. Viewing, printing and distributing a graphic such as our threat map has the potential to serve as a similar, personnel protection aid.

In the present study, we demonstrated the effects of including vegetation density and levels of disturbance in predictive models that describe tick distributions. The former was marginally important to the distribution of nymphs and adults. However, the latter clearly illustrated that levels of disturbance, or stages of succession, are potentially more important to the larval population than is the vegetation community. Vegetation maps are increasingly being used by personnel on public-use and military lands, and vegetation density is one of the factors that can be rapidly extracted from georeferenced databases. Levels of disturbance are a qualitative measurement that can be assessed on site, and thus, need to be implemented both systematically and consistently, as was done throughout this investigation. Future vector population modeling investigations will probably include other qualitative categories that, $a$ priori, might seem unimportant to the vector or the host population. Perhaps these remain undetected because of the problems that arise from scale or habitat heterogeneity, as well as the tendency for statistically significant parameters to mask their effects. More complex sampling procedures and analytical techniques than those used in this study will probably result in our ability to predict tick densities among habitat patches that vary in quality. Accordingly, we need to focus on the movements of ticks during each life stage, the movements and behaviour of their mammalian hosts and develop better tick sampling methodology. Campbell and Mackay (1979) have suggested using a combination of techniques, including radio-telemetry of mammals, and radioisotope tagging of ticks (Sonenshine, 1993). These techniques are labor intensive, and one can easily imagine the difficulties involved with data interpretation; however, the data resulting from tick and host movements are critical for determining patch size. When this information is combined with newer, high-resolution remotely-sensed images and recent vegetation/habitat maps, we will then have the capacity to develop threat and risk maps that accurately predict the probable locations of vectors and the diseases that they transmit.

\section{Acknowledgements}

The authors wish to thank the following individuals for their review of this manuscript: Robert H. Giles, Jr. (Prof. Emeritus, Virginia Tech), Glen R. Needham (Department of Entomology, The Ohio State University), Charles H. King (Center for Global Health and Diseases, Case Western University) and Eric P. Smith (Department of Statistics, Virginia Tech). We also thank Robert Wheeler for his encouragement throughout this project. We are especially grateful to Scott Klopfer for his assistance with GIS. We are indebted to Karl Neidhardt, Melissa Miller and Alexandra Spring for their 
support and laboratory assistance throughout this investigation. This research was supported by the Virginia Department of Military Affairs, Fort Pickett, VA. Finally, Kenneth J. Stein thanks Clara, his wife, who volunteered many hours of her time to help him collect ticks and assess habitats.

\section{References}

Agresti A, 2002. Categorical data analysis, 2nd ed, John Wiley, Interscience, New York, USA, pp. 734.

Bartlett IH, 1938. Whitetails, presenting Michigan's deer problem. Michigan Department of Conservation, Bull Game Div, 1-64.

Bloemer SR, Zimmerman RH, Fairbanks K, 1988. Abundance, attachment sites, and density estimators for lone star ticks (Acari: Ixodida) infesting white-tailed deer. J Med Entomol 25, 295-300.

Braun EL, 1950. Deciduous forests of eastern North America. Blakiston Co, Philadelphia, PA, USA, 596 pp.

Bunnell JE, Price SD, Das A, Shields TM, Glass GE, 2003. Geographic information systems and spatial analysis of adult Ixodes scapularis (Acari: Ixodidae) in the Middle Atlantic region of the U.S.A. J Med Entomol 40, 570-576.

Burkot TR, Mullen GR, Anderson R, Schneider BS, Happ CM, Zeidner NS, 2001. Borrelia lonestari DNA in adult Amblyomma americanum ticks, Alabama. Emerg Infect Dis 7, 471-473.

Campbell A, Mackay PR, 1979. Distribution of the American dog tick, Dermacentor variabilis (Say), and its small-mammal hosts in relation to vegetation types in a study area in Nova Scotia. Can J Zool 57, 1950-1959.

Childs JE, Paddock CD, 2003. The ascendancy of Amblyomma americanum as a vector of pathogens affecting humans in the United States. Ann Rev Entomol 48, 307-337.

Chilton NB, Bull CM, 1993. Interspecific differences in microhabitat choice by two species of Australian reptile tick. Int J Parasitol 23, 1045-1051.

Daniel M, Dusbábek F, 1994. Micrometeorological and microhabitat factors affecting maintenance and dissemination of tick-borne diseases in the environment. In: Ecological dynamics of tick-borne zoonoses. DE Sonenshine, TN Mather (eds). Oxford University Press, New York, USA, p. 464.

Daniels TJ, Fish D, 1990. Spatial distribution and dispersal of unfed larval Ixodes dammini (Acari: Ixodidae) in Southern New York. Environ Entomol 19, 1029-1033.

Estrada-Peña A, 2002. Understanding the relationships between landscape connectivity and abundance of Ixodes ricinus ticks. Exp Appl Acarol 28, 239-248.

Estrada-Peña A, Venzal JM, 2007. A GIS framework for the assessment of tick impact on human health in a changing climate. Geospatial Health 1, 157-168.

Falco RC, Fish D, 1988. Prevalence of Ixodes dammini near the homes of Lyme disease patients in Westchester County, New York. Am J Epidemiol 127, 826-830.

Falco RC, Fish D, 1991. Horizontal movement of adult Ixodes dammini (Acari: Ixodidae) attracted to $\mathrm{CO}_{2}$ baited traps. J Med Entomol 28, 726-729.

Gambel JM, Brundage JF, Burge RJ, DeFraites RF, Smoak BL, Wirtz RA, 1998. Survey of U.S. Army soldiers' knowledge, attitudes, and practices regarding personal protection measures to prevent arthropod-related diseases and nuisance bites. Mil Med 163, 695-701.

Giles RH Jr, 1978. Habitat analysis and design. In: Wildlife Management, WH Freeman and Company, San Francisco, CA, USA, pp. 416.

Glass GE, Schwartz BS, Morgan III JM, Johnson DT, Noy PM, Israel E, 1995. Environmental risk factors for Lyme disease identified with geographic information systems. Am J Publ Health 85, 944-948.

Goddard J, 1997. Clustering effects of lone star ticks in nature: implications for control. J Environ Health 59, 8-11. Haile DG, Mount GA, 1987. Computer simulation of population dynamics of the lone star tick, Amblyomma americanum (Acari: Ixodidae). J Med Entomol 24, 356-369.

Hopla CE, Hopla AK, 1994. Tularemia. In: Handbook of Zoonoses, 2nd ed. GW Beran and JH Steele (eds). CRC Press, Inc, Boca Raton, p. 560.

Kitron U, 2000. Risk maps: transmission and burden of vector-borne diseases. Parasitol Today 16, 324-325.

Kleinbaum, DG, Kupper LL, Muller KE, 1988. Applied regression analysis and other multivariable methods. PWSKent Publishing, Boston, MA, USA, 718 pp.

Klomp NI, Bull CM, 1987. Responses to environmental cues by unfed larvae of the Australian reptile ticks Aponomma bydrosauri and Amblyomma limbatum. J Parasitol 73, 462466.

Koch HG, 1984. Survival of the lone star tick, Amblyomma 
americanum (Acari: Ixodidae), in contrasting habitats and different years in southeastern Oklahoma, USA. J Med Entomol 21, 69-79.

Leopold A, 1933. Game management. Charles Scribner's Sons, NY, USA, pp. 481.

Lockhart JM, Davidson WR, Stallknecht DE, Dawson JE, Little SE, 1997. Natural history of Ehrlichia chaffeensis (Rickettsiales: Ehrlichieae) in the Piedmont physiographic province of Georgia. J Parasitol 83, 887-894.

Morton DD, 1998. Landcover of Virginia from LANDSAT thematic mapper imagery. MS Thesis, College of Forestry and Wildlife Resources, Virginia Polytechnic Institute and State University, Blacksburg, VA, USA, pp. 253.

Mount GA, Haile DG, Barnard DR, Daniels E, 1999. Integrated management studies for Amblyomma americanum (Acari: Ixodidae) in non-agricultural areas. Exp Appl Acarol 23, 827-839.

Nicholson MC, Mather TN, 1996. Methods for evaluating Lyme disease risks using geographic information systems and geospatial analysis. J Med Entomol 33, 711-720.

Norval RAI, 1974. The life cycle of Amblyomma hebraeum Koch 1844 (Acarina: Ixodidae). J Entomol Soc S Afr 37, 357-367.

Ostfeld RS, Cepeda OM, Hazler KR, Miller MC, 1995. Ecology of Lyme disease: habitat associations of ticks (Ixodes scapularis) in a rural landscape. Ecol Appl 5, 353-361.

Ostfeld RS, Hazler KR, Cepeda OM, 1996a. Temporal and spatial dynamics of Ixodes scapularis (Acari: Ixodidae) in a rural landscape. J Med Entomol 33, 90-95.

Ostfeld RS, Jones CG, Wolff JO, 1996b. Of mice and mast: ecological connections in eastern deciduous forests. Bioscience 46, 323-330.

Patrick CD, Hair JA, 1979. Oviposition behavior and larvae longevity of the lone star tick, Ambylomma americanum (Acarina: Ixodidae) in different habitats. Ann Entomol Soc Am 72, 308-312.

Petney TN, Bull CM, 1984. Microhabitat selection by two reptile ticks at their parapatric boundary. Aust J Zool 9, 233-239.

Schulze TL, Jordan RA, Healy SP, Roegner VE, Meddis M, Jahn MB, Guthrie DL, 2006. Relative abundance and prevalence of selected Borrelia infections in Ixodes scapularis and Amblyomma americanum (Acari: Ixodidae) from publicly owned lands in Monmouth County, New Jersey. J
Med Entomol 43, 1269-1276.

Semtner PJ, Barker RW, Hair JA, 1971a. The ecology and behavior of the lone star tick (Acarina: Ixodidae): II. Activity and survival in different ecological habitats. J Med Entomol 8, 719-725.

Semtner PJ, Hair JA, 1973. The ecology and behavior of the lone star tick (Acarina: Ixodidae): V. Abundance and seasonal distribution in different habitat types. J Med Entomol 10, 618-628.

Semtner PJ, Howell DE, Hair JA, 1971b. The ecology and behavior of the lone star tick (Acarina: Ixodidae): I. The relationship between vegetative habitat type and tick abundance and distribution in Cherokee Co., Oklahoma. J Med Entomol 8, 329-335.

Slowik TJ, Lane RS, 2001. Nymphs of the western blacklegged tick (Ixodes pacificus) collected from tree trunks in woodland grass habitat. J Vector Ecol 26, 165-171.

Sonenshine DE, 1993. Biology of ticks, Vol. 2. Oxford University Press, New York, USA, pp. 465.

Sonenshine DE, Atwood EL, Lamb JT, 1966. The ecology of ticks transmitting Rocky Mountain Spotted fever in a study area in Virginia. Ann Entomol Soc Am 59, 1234-1262.

Sonenshine DE, Levy GF, 1972. Ecology of the American dog tick, Dermacentor variabilis, in a study area in Virginia. 2. Distribution in relation to vegetative types. Ann Entomol Soc Am 65, 1175-1182.

Sonenshine DE, Ratzlaff R, Troyer J, Demmerle S, Demmerle ER, Austin WE, Tan S, Annis BA, Jenkins S, 1995. Borrelia burgdorferi in eastern Virginia: comparison between a coastal and inland locality. Am J Trop Med Hyg 53, 123-133.

Statistical Analysis System (SAS), 1998. Version 6.12, SAS Institute, Cary, NC, USA.

Stromdahl EY, Randolph MP, O’Brien JJ, Gutierrez AG, 2000. Ehrlichia chaffeensis (Rickettsiales: Ehrlichieae) infection in Amblyomma americanum (Acari: Ixodidae) at Aberdeen Proving Ground, Maryland. J Med Entomol 37, 349-356.

Van Buskirk J, Ostfeld, RS, 1998. Habitat heterogeneity, dispersal, and local risk of exposure to Lyme disease. Ecol Appl 8, 365-378.

Wilson JG, Rinzer DR, Sauer JR, Hair JA, 1972. Chemoattraction in the lone star tick (Acarina: Ixodidae): I. Response of different developmental stages to carbon dioxide administered via traps. J Med Entomol 9, 245-252. 